\title{
CATARACT SURGICAL UPTAKE AMONG OLDER ADULTS IN GHANA
}

\author{
E.M ACKUAKU-DOGBE ${ }^{1}$, A.E YAWSON ${ }^{2,3}$ and R.B BIRITWUM ${ }^{2}$ \\ ${ }^{1}$ Department of Surgery, Eye Unit, University of Ghana Medical School, College of Health Sciences, Accra, \\ Ghana ${ }^{2}$ Department of Community Health, University of Ghana Medical School, College of Health Sciences, \\ Accra, Ghana ${ }^{3}$ Public Health Unit, Korle-Bu Teaching Hospital, Korle-Bu, Accra, Ghana
}

DOI: http://dx.doi.org/10.4314/gmj.v49i2.4

Corresponding Author: E.M Ackuaku-Dogbe

E-mail: edithackuaku@yahoo.com

Conflict of Interest: None declared

\section{SUMMARY}

Objectives: In sub-Saharan Africa, cataract surgical services are highly inadequate and surgical uptake for cataract is low. This paper describes cataract surgical uptake among older adults in Ghana.

Methods: This work was based on World Health Organization's multi-country Study on global Ageing and adult health (SAGE), conducted in six countries including Ghana. Wave one of SAGE in Ghana was conducted in 2007-2008 as collaboration between WHO and Department of Community Health, University of Ghana Medical School. A nationally representative sample of 5571 older adults ( $\geq 50$ years) and a small sample of persons 18-49 years were interviewed. Data was obtained on uptake of cataract surgery in older adults and analyzed using descriptive measures and chi square for associations in categorical outcome measures.

Results: Overall surgical uptake was 48.9\% among older adults and was slightly higher among older men (49.1\%) than women (48\%). Cataract surgical uptake was relatively higher in the 60-69 years group (55\%), urban residents $(52.6 \%)$ and those living without partners $(50 \%)$. Educational and income levels of older persons did not affect cataract surgical uptake. Regional differences in cataract surgical uptake existed; was less than $60 \%$ in all ten regions (except one), and the two regions with most self-reported cataracts (Ashanti and Greater Accra) had less than 50\% uptake.

Conclusions: Intensive public education, engagement of community groups and increased access to cataract surgery at health facilities and outreach services need consideration at national/sub-national levels. Further investigations to garner equity in national eye care efforts are recommended.

Keywords: Older adult, cataract, cataract surgical uptake, regions, Ghana

\section{INTRODUCTION}

Cataract remains the major cause of blindness and low vision worldwide. ${ }^{1}$ In Ghana, regional surveys conducted in $\mathrm{Wenchi}^{2}$ and the Volta region ${ }^{3}$ indicate that cataract contributed to $62.5 \%$ (in persons 30 years and above) and $53.9 \%$ (in those 40 years and above) respectively. Cataract surgery remains the mainstay treatment of cataract blindness. Management of cataract largely centers on the removal of the opacified lens and correcting the resulting hypermetropia with an intraocular lens implant. ${ }^{4}$

Surgical intervention has been found to have greater cost benefits (including intangible benefits like increased sight) compared to no surgical intervention for those with cataract. ${ }^{5,6}$ Despite these obvious benefits of cataract surgery, cataract remains the leading cause of blindness in Ghana as a result of a number of barriers between patients and the available services.

The 2005 annual Ghana eye care report indicated that the total cataract operations performed nationwide represented only $25 \%$ of total need to reach the Vision 2020 target. $^{7}$ Several other studies in developing countries report low levels of cataract surgical uptake. ${ }^{8-10}$ Sex variations in cataract surgical uptake have been suggested as well. A WHO meta-analysis of cataract surveys in developing countries, indicated that the cataract surgical uptake rate was 1.2 to 1.7 times higher for males than for females. ${ }^{11}$

Several factors have been attributed to low uptake of cataract surgery, including cost, lack of knowledge and access, and fear of surgery among others. ${ }^{8-11}$ The barriers and rates of uptake of cataract surgery are not uniform within and between countries. In a study in the Upper East Region of Ghana, 91\% of respondents mentioned cost as the main barrier to uptake and $12 \%$ mentioned fear of surgery. 4 
In South Africa for example, the main cause of low uptake was identified as fear of surgery and its complications. $^{10}$

The goal of this analysis is to describe the patterns in self-reported cataract and cataract surgical update among older adults and to demonstrate sex and regional differences in cataract surgical uptake in Ghana. Knowledge of uptake rates, sex and regional distribution should assist in planning intervention for areas of low uptake and this should lay the foundations for regional studies to determine the causes of low uptake in each region.

\section{METHODS}

The Study on global AGEing and adult health (SAGE) survey was undertaken in Ghana, in a partnership between the University of Ghana's Department of Community Health, the Ministry of Health and WHO, as part of a multi-country longitudinal study to complement existing ageing data sources to inform policy goals and programmes. The World Health Organization's Study on global AGEing and adult health evolved from the 2002/04 World Health Survey (WHS). SAGE is being carried out in six countries; China, Ghana, India, Mexico and the Russian Federation and South Africa.

This study is based on data from SAGE Wave 1 in Ghana, with the goal of providing evidence to implement the national ageing policy in Ghana. ${ }^{12}$ A nationally representative sample was used for the survey. Respondents 50 years and above were interviewed regarding their household characteristics, socio-demographic and work history, perceived health status, risk factors and preventive health behaviours, chronic conditions and health services coverage, health care utilization, subjective well-being and quality of life, and social cohesion. In addition, anthropometric measurements were recorded and blood spots for biomarkers were collected. Respondents also completed performance tests.

Field work and data entry were undertaken between May 2007 and June 2008. SAGE has been approved by the World Health Organization's Ethical Review Board and the Ethics and Protocol Committee of the University of Ghana Medical School. Informed consent was obtained from all study participants. Detailed sampling techniques for the SAGE Wave 1 survey in Ghana have been described in published materials and a detailed national report. ${ }^{12-14}$

\section{Measures}

Demographic and socioeconomic variables: include sex, age, location (urban/rural), region of residence, marital status, highest educational level completed, health insurance status and household income levels. Ghana operates a social health insurance policyNational Health Insurance Scheme- introduced in 2003 and became operational in most health public and private health facilities in 2005 .

There are a few private, voluntary and mutual health insurance schemes operated by health and corporate organizations in the urban centers. Educational level was categorized as low (primary or basic school completed or less) and high (at least secondary school completed or higher).

Cataract: Two questions were asked: "In the last 5 years, were you diagnosed with a cataract in one or both of your eyes or cloudiness in the lens of the eye)?" and "In the last 5 years, have you had eye surgery to remove this cataract(s)?". ${ }^{13}$ Diagnosis of cataract in the health care system of Ghana is by a doctor or nurse trained in ophthalmology.

Wealth or income quintiles were derived from the household ownership of durable goods, dwelling characteristics and access to services (improved water, sanitation and cooking fuel) for a total of 21 assets. Wealth levels were generated through a multi-step process, where asset ownership was converted to an asset ladder, Bayesian post-estimation method used to generate raw continuous income estimates, and then income transformed into quintiles. ${ }^{14}$ For this analysis, income was categorized in to lower (Q1, Q2 and Q3) and higher (Q4 and Q5).

\section{Data Analysis}

Associations between cataract and demographic and socioeconomic indices were evaluated using chi square and odds ratio (OR) at the $95 \%$ confidence level. Demographic and socio-economic variables used included age, region of residence, location (urban/ rural), educational level, marital status, and income levels. Data was weighted and age-standardized and analyzed using SPSS version 21 .

\section{RESULTS}

In all, 231 older adults reported to have been diagnosed with cataract in one or both eyes within the last five years. Of these, $111(48.9 \%)$ reported to have had cataract surgery. Therefore for this analysis, overall cataract surgical uptake among older adults in Ghana was $48.5 \%$.

Table 1 indicates surgical uptake for older men and women. Among 122 older women who have been diagnosed with cataract, 59 (48.4\%) have had cataract surgery; while a slightly greater number 63 (51.6\%) 
have not had surgery. Among older men, 52 (49.5\%) of the 105 who have been diagnosed with cataract, have had cataract surgery, while $53(50.5 \%)$ have not had cataract surgery. In terms of proportions of those diagnosed with cataract who have had surgery, older men had an uptake of $49.5 \%$ while the uptake was marginally lesser for the older women, $48.4 \%$.

Table 1 Prevalence of cataracts surgical uptake in older adults by demographic and socioeconomic characteristics, SAGE Wave 1, Ghana

\begin{tabular}{|c|c|c|c|}
\hline \multirow[b]{2}{*}{ Characteristics } & $\begin{array}{l}\text { Prevalence } \\
\text { of cataract } \\
\text { surgery in } \\
\text { last } 5 \text { years } \\
\end{array}$ & $\begin{array}{l}\text { Self- } \\
\text { reported } \\
\text { diagnosed } \\
\text { cataract } \\
\end{array}$ & \multirow[t]{2}{*}{$\mathrm{X}^{2}$ (p-value) } \\
\hline & $\mathrm{n}(\%)$ & $(\mathrm{N}=231)$ & \\
\hline \multicolumn{4}{|l|}{ Sex } \\
\hline Male & $53(49.1)$ & 107 & $0.28(0.867)$ \\
\hline Female & $60(48)$ & 124 & \\
\hline \multicolumn{4}{|l|}{ Age group } \\
\hline $50-59$ & $13(34.2)$ & 38 & \\
\hline $60-69$ & $33(55)$ & 60 & $4.19(0.123)$ \\
\hline $70+$ & $66(49.6)$ & 133 & \\
\hline \multicolumn{4}{|l|}{ Residence } \\
\hline Urban & $61(52.6)$ & 116 & $1.57(0.210)$ \\
\hline Rural & $51(44.3)$ & 115 & \\
\hline \multicolumn{4}{|l|}{ Marital status } \\
\hline Never married & $1(25)$ & 4 & \\
\hline $\begin{array}{l}\text { Living with partner (mar- } \\
\text { ried/cohabiting) }\end{array}$ & $51(47.7)$ & 107 & $1.02(0.600)$ \\
\hline $\begin{array}{l}\text { Living without partner } \\
\text { (Separated/divorced/ } \\
\text { Widowed) }\end{array}$ & $60(50)$ & 120 & \\
\hline \multicolumn{4}{|l|}{ Highest educational level } \\
\hline $\begin{array}{l}\text { Primary school complet- } \\
\text { ed or less }\end{array}$ & $59(56.3)$ & 104 & $0.20(0.886)$ \\
\hline $\begin{array}{lll}\begin{array}{l}\text { Secondary } \\
\text { above }\end{array} & \text { school and } \\
\end{array}$ & $72(57.6)$ & 127 & \\
\hline \multicolumn{4}{|l|}{ Income quintile } \\
\hline Q1, Q2 and Q3 (lower) & $52(47.7)$ & 111 & $2.02(0.364)$ \\
\hline Q4 and Q5 (higher) & $60(50)$ & 120 & \\
\hline \multicolumn{4}{|l|}{ Health Insurance } \\
\hline Yes & $64(54.7)$ & 117 & $3.67(0.055)$ \\
\hline No & $48(42.1)$ & 114 & \\
\hline Total respondents & $122(48.5)$ & 231 & \\
\hline
\end{tabular}

Self-reported cataract increased with age in the older adults; however the highest proportion of cataract surgical uptake was 55\% among the 60-69 year age group. Only half of the 133 older adults 70 years and above have had cataract surgery. Cataract surgical uptake was slightly higher among urban residents $52.6 \%$ and also among those living without partner (Separated/ divorced/ Widowed) (50\%) compared to those living with partner (married/cohabiting) (47.7\%). Educational level of the older adults did not greatly influence cataract surgical uptake as shown in Table 1.

High income seems to increase cataract surgical uptake marginally (50\%) compared to $47.7 \%$ in older adults with low income, however this difference was not statistically significant. Cataract surgical uptake was significantly higher among older adults with national health insurance $(54.7 \%)$ compared to those without national health insurance (42.1).

Regional differences existed in prevalence of selfreported diagnosed cataract and reported cataract surgeries among older adults in Ghana. In terms of proportions of persons self-reporting diagnosed cataract (as shown in Table 2), Greater Accra region had the highest prevalence, $10.1 \%$, followed by Central region, $6.2 \%$ and then Volta region, 5.8\%. The Upper East and Northern regions had the lowest prevalence of $1.9 \%$ and $2.6 \%$ respectively.

Cataract surgical uptake per region indicated that, all the regions (except the Brong-Ahafo) had uptake rates of less than $60 \%$; the Brong- Ahafo had the highest uptake of $66.7 \%$, followed by Volta, $58.3 \%$ and then Eastern, $56.7 \%$. It is important to note that the two regions with the highest number of self-reported cataracts (Greater Accra and Ashanti) had cataract surgical uptake rates of less than $50 \%$.

Table 2 Regional prevalence of self-reported cataract and cataract surgical uptake among older adults, SAGE Wave 1, Ghana

\begin{tabular}{|l|l|l|l|l|}
\hline \multirow{2}{*}{ Region } & \multicolumn{3}{|c|}{$\begin{array}{l}\text { Cataract surgery } \\
\text { in last 5 years }\end{array}$} \\
\cline { 2 - 5 } & $\mathrm{n}(\%)$ & $\mathrm{N}$ & $\mathrm{n}(\%)$ & $\mathrm{N}$ \\
\hline Ashanti & $32(4.7)$ & 697 & $15(45.5)$ & 33 \\
\hline Brong Ahafo & $15(3.7)$ & 409 & $10(66.7)$ & 15 \\
\hline Central & $28(6.2)$ & 452 & $13(44.8)$ & 29 \\
\hline Eastern & $30(5.4)$ & 557 & $17(56.7)$ & 30 \\
\hline Greater Accra & $50(10.1)$ & 493 & $26(51)$ & 51 \\
\hline Northern & $10(2.6)$ & 385 & $4(40)$ & 10 \\
\hline Upper East & $5(1.9)$ & 260 & $1(20)$ & 5 \\
\hline Upper West & $6(4.5)$ & 132 & $1(14.3)$ & 7 \\
\hline Volta & $24(5.8)$ & 411 & $14(58.3)$ & 24 \\
\hline Western & $27(5.3)$ & 511 & $11(40.7)$ & 27 \\
\hline Total & 5.3 & 4278 & 48.5 & 231 \\
\hline
\end{tabular}

\section{DISCUSSION}

Studies have shown that availability of cataract surgical services do not necessarily translate to adequate cataract surgical uptake ${ }^{15,16}$ and that barriers to uptake of cataract surgery at the individual level prevent a large 
proportion of persons with cataract from being cured. $^{17,18}$

On the other hand, evidence indicates that a disproportionate number of global cataract blind live in subSaharan Africa where cataract surgical services are highly inadequate and might be the main reason for low cataract surgical uptake in this region. ${ }^{19}$ The experience of most Ghanaian ophthalmologists is that, usually a significant number of patients screened for cataract surgery do not report for surgery, whether on outreach services, eye camps or within hospitals. It is therefore useful to determine the uptake levels and associated factors in individual communities for the purposes of planning cataract surgical services.

The overall cataract surgical uptake was $48.9 \%$ (with a slight male preponderance $49.1 \%$ vs. $48 \%$ ). This finding conforms to that found in a study in Nepal, where of 319 cataract patients identified only $45.5 \%$ accepted surgery, with men accepting surgery more readily than women. ${ }^{18}$ The Nepal study was based on field examination rather than self-reporting by patients, which was the case for SAGE Wave 1 national survey among older adults in Ghana, yet similar uptake of cataract surgery were reported. Some studies have indeed shown that self-report by older adults of some medical conditions compare favorably with their medical record reports. $^{20}$

It has been established that women bear approximately two-thirds of the global burden of blindness, with cataract being the major cause in developing countries. ${ }^{21}$ It has been suggested that much of the excess female blindness in these countries might be due to cataract. ${ }^{22}$ A meta-analysis of cataract surveys in developing countries showed that the cataract surgical uptake rate was 1.2 to 1.7 times higher for males than for females. ${ }^{11}$ In that analysis, the odds ratio of having surgery was lower for females compared to males; females accounted for approximately $63 \%$ of all cataract cases in the population studied. The study suggested that if females received surgery at the same rates as males, the prevalence of cataract blindness would be greatly reduced (by a median of $12.5 \%$; range $4 \%-21 \%$ ). ${ }^{11}$

In the Nepal study mentioned above ${ }^{18}$, though the female population was more likely to have visual impairment due to cataract than the male population, the men more readily accepted surgery. The reasons attributed to the differences in cataract surgical uptake by men and women were the gender roles of males and females of the age group, with the male population being more mobile and the female population being more confined to the traditionally accepted roles within the household. ${ }^{18}$
Gender differentials and cultural differences in different ethnic groups make it useful to determine the causes of lower uptake in different parts of the country in the national effort to improve cataract surgical uptake. Apart from sex differences, our analysis demonstrated other sociodemographic differences in cataract surgical uptake. Surgical uptake varied with age, the highest proportion was among the 60-69 year age group (55\%) and lowest in the 50-59 year group (34.2\%). Among persons 70 years and above, only $49.6 \%$ had surgery for cataract. These findings potentially could be that at the age of 60-69 years, the cataracts are matured and the older persons being relatively more mobile and independent can access an eye care service. In those 70 years and above, though the cataracts may be matured, other socio-economic conditions, reduced mobility, dependency and health and social challenges may come to play.

In our analysis, the relatively younger age group among the older adults (50-59 years) had the lowest surgical uptake probably because the cataracts may not be so mature as to result in such visual impairment that would compel them to accept surgery. In conformity with this finding, a national survey in Pakistan showed cataract surgical uptake to be dependent on the level of visual acuity, and was higher among those with lower visual acuity. ${ }^{22}$

Apart from age and sex differences, cataract surgical uptake was found to be slightly higher among urban residents $(52.6 \%)$ and also among those living without partner (separated/ divorced/ widowed) (50\%) compared to those living with partner (married/cohabiting) $(47.7 \%)$. The urban -rural differences in cataract surgical uptake was similar to that found in the national survey in Pakistan, where cataract surgical uptake was higher in urban than rural areas. ${ }^{22}$ This difference in surgical uptake by geolocality may be primarily due to access to services. In Ghana cataract services are concentrated in urban areas. Equity in access to eye health care services through extensive outreach services to rural communities to capture older adults with cataract will greatly improve national coverage.

In contrast to findings in the national survey in Pakistan where surgical uptake was significantly higher in literate participants ${ }^{22}$, educational level did not greatly influence cataract surgical uptake in this analysis of national survey data in older adults in Ghana. That literacy does not significantly affect uptake might suggest that our health education efforts regarding the need for surgery to restore sight to the cataract blind may be yielding some results or that access is the main hindrance. 
The older person may be aware of the need to have surgery; however he/she may be encumbered with issues regarding access to health service including availability of the service, personal cost, and cost of health care and other opportunity cost.

Interestingly, the level of income did not seem to have any significant impact on cataract surgical uptake in our analysis. This observation may be linked to the finding that cataract surgical uptake was significantly higher among those covered with national health insurance $(54.7 \%)$ compared to those without health insurance, (42.1\% of). Thus improving public education, engagement of community group (such as the queen mothers and other female groups) and increasing access to cataract surgery at health facilities and through outreach services need to be considered at national and sub-national levels.

The regional analysis suggests a lot of inequity in cataract surgical uptake. Surgical uptake per region indicated that, all the regions (except one) had uptake rates of less than $60 \%$. Also, it is important to note that the two regions with the highest number of self-reported cataracts (Greater Accra and Ashanti) had cataract surgical uptake rates of less than $50 \%$. The regional differences need further investigation regarding access and availability of cataract surgery for the population and other sociocultural and religious factors pertaining in the regions. Factors such as cultural differences, distribution of cataract surgical services and incentives for these services may interplay. For equity, these factors must be identified and addressed.

Limitation: Calling other blinding diseases cataract and labeling any ocular/ orbital/ adnexal surgical procedures as cataract surgery by the older adults are likely. The Ghana SAGE Wave 1 relied on individual submissions and did not objectively confirm cataract surgery. In the survey however, the questions referred to the last five years to minimize the potential recall bias $^{13}$. The SAGE national survey did not collect data on the reasons for the heath seeking behaviour of older persons concerning chronic conditions and thus this analysis could not provide the reasons for low cataract uptake. It has however, provided baseline information on low cataract uptake among older persons across the regions of Ghana for further investigations.

\section{CONCLUSION AND RECOMMENDA- TION}

Overall surgical uptake was $48.9 \%$ among older adults in Ghana. Cataract surgical uptake varied by age groups, sex, location (rural/urban), marital status and by administrative regions in Ghana.
Educational and income levels of older persons did not affect cataract surgical uptake. Intensive public education and gender-sensitive intervention programmes through engagement of community groups (such as queen mothers and other female groups) - will be critical in improving cataract surgical uptake particularly among older adult women in Ghana and similar settings. Increased access to cataract surgical services at health facilities and through outreach clinics at national and sub-national levels need attention in national eye care programmes. Regional and sociocultural differences in access to care and availability of cataract surgery need further investigation to garner equity in national eye care efforts.

\section{ACKNOWLEDGEMENT}

We are grateful to all respondents and interviewers who made the SAGE survey in Ghana possible. Financial support was provided by the US National Institute on Aging through Interagency Agreements (OGHA 04034785; YA1323-08-CN-0020; Y1-AG-1005-01) with the World Health Organization and a Research Project Grant (R01 AG034479- 64401A1). WHO contributed financial and human resources to SAGE. The Ministry of Health, Ghana, is supportive of SAGE. The University of Ghana's Department of Community Health contributed training facilities, data entry support, and storage of materials. The Ghana Statistical Office provided the sampling information for the sampling frame and updates.

\section{REFERENCES}

1. WHO Library Cataloguing-in-Publication Data. Global Initiative for the Elimination of Avoidable Blindness : action plan 2006-2011

2. Moll AC, Van der Linder AJH, Hogeweg M, Schader WE, Hermans J, De Keizer. Prevalence of blindness and low vision of people over 30 years in the Wenchi district, Ghana, in relation to eye care programmes. British Journal of Ophthalmology 1994; 78: 275-279

3. Guzek JP, Anyomi FK, Fiadoyor S, Nyonator F. Prevalence of blindness in people over 40years in the Volta Region of Ghana. Ghana Medical Journal 2005; 39(2) : 52-62

4. Gyasi ME, Amoaku WMK, Asamany DK. Barriers to cataract surgical uptake in the Upper East region of Ghana. Ghana Medical Journal 2007; 80(4):288-292

5. Bernth-Petersen P. Outcome of cataract surgery: socio-economic aspects. Acta Ophthalmol 1982;60:461-468

6. Tuominen R, Immonen I. economic evaluation of cataract surgery: a comparison between IOL and 
non IOL Techniques. Acta Ophthalmol 1988; 66:577-581

7. Annual Eye Care Report - Ghana Eye Foundation. Published by the Ghana Eye Foundation, 2005.

8. Snelligen P, Shrestha et al. Socio-economic barriers to cataract surgery in Nepal: the South Asian cataract management study. British Journal of Ophthalmology 1998; 82:1424-1428

9. Courtright S, Kanjaloti S, Lewallen S. Barriers to acceptance of cataract surgery among patients presenting to district hospital in rural Malawi. Trop and Geogra Med 1995; 47:15-18

10. Rotchford AP, Rotchford KM, Mthethwa LP, Johnson GJ. Reasons for poor cataract surgery uptake - a qualitative study in rural South Africa. Tropical Medicine and International Health 2002;7 (3): 288-292

11. Lewallen S, Courtright P. Gender and use of cataract surgical services in developing countries. Bull World Health Organ 2002; 80(4):300-3

12. University of Ghana, Department of Community Health. Ghana National Report on World Health Organization's Study on global AGEing and adult health (SAGE) in Ghana, Wave 1. Geneva:WHO. 2013.

13. Kowal P, Chatterji S, Naidoo N, Biritwum R, Wu Fan, Lopez Ridaura R, Maximova T, Arokiasamy P, Phaswana-Mafuya N, Williams S, Snodgrass JJ, Minicuci N, D'Este C, Peltzer K, Boerma JT, and the SAGE Collaborators. Data Resource Profile: The World Health Organization Study on global AGEing and adult health (SAGE). Int J Epidemiol. 2012;1-11. doi:10.1093/ije/dys210

14. Biritwum RB, Mensah G, Minicuci N, Yawson AE, Naidoo N, Chatterji S, Kowal P. Study on global AGEing and adult health in Ghana: Methodology and household characteristics in Wave 1. Glob Health Action. 01/2013; 6:20096. DOI:dx. doi.org/ 10.3402/ gha.v6i0.20096.
15. Fletcher A. Barriers to using eye services and recommendation to improve service uptake. Research finding and international workshop recommendation. Madurai, India 1998:10.

16. Rotchford AP, Rotchford KM, Mthethwa LP, Johnson GJ. Reasons for poor cataract surgery uptake - a qualitative study in rural South Africa. Tropical Medicine and International Health 2002;7 (3): 288-292

17. Brilliant G, Lepkowski J, Zurita B, Thulasiraj R. Social determinants of cataract surgery utilization in South India. Archives of Ophthalmology 1991; 109:584-589.

18. Snellingen T, Shrestha BR, Gharti MP, Shrestha JK, Upadhyay MP, Pokhrel RP () Socioeconomic barriers to cataract surgery in Nepal: the South Asian cataract management study. British Journal of Ophthalmology 1998; 82: 1424-1428.

19. Foster A. Who will operate on Africa's 3 million curably blind people? Lancet 1991; 337: 12671269.

20. Bush T L, Miller S R, Golden A L, Hale W E. Self-report and medical record report agreement of selected medical conditions in the elderly. American Journal of Public Health 1989;79 (11): 15541556

21. Abou-Gareeb I, Lewallen S, Bassett K, Courtright P. Gender and blindness: a meta-analysis of population-based prevalence surveys. Ophthalmic Epidemiology 2001;8:39-56.

22. Jadoon Z, Shah S P, Bourne R, B Dineen, Khan M A, Gilbert C E, Foster A, Khan M D Cataract prevalence, cataract surgical coverage and barriers to uptake of cataract surgical services in Pakistan: the Pakistan National Blindness and Visual Impairment Survey. British Journal of Ophthalmol 2007;91:1269-1273 